\title{
Tensions in management roles in contemporary healthcare organisations
}

Scott A, Timmons S (2017) Tensions in management roles in contemporary healthcare organisations. Nursing Management.

Date of submission: 18 August 2016; date of acceptance: 28 November 2016. doi:

10.7748/nm.2017.e1569

\section{Anne Scott}

Deputy chief nurse, East Leicestershire and Rutland Clinical Commissioning Group, Leicester, England

Stephen Timmons

Senior lecturer, University of Nottingham Business School, England

Correspondence

anne.scott@eastleicestershireandrutlandccg.nhs.uk

Conflict of interest

None declared

Peer review

This article has been subject to external double-blind peer review and checked for plagiarism using automated software

Online

For related articles visit the archive and search using the keywords. Guidelines on writing for publication are available at: journals.rcni.com/r/author-guidelines

\section{Abstract}

Aim This article reports the results of a study that gives an insight into ward leaders' perspectives of their leadership role and explores how they deliver leadership at ward level within organisational constraints and processes. Previous studies have been evaluations of clinical leadership in general, or literature reviews of the ward leader role. The aim of this study was to examine the leadership role of ward sisters and to understand how they lead quality of care on their wards.

Methods A qualitative methodology was used, incorporating 19 in-depth interviews with ward leaders and modern matrons.

Results Three main themes were identified: empty conformity, authority and autonomy, and visibility and leading by example. Participants aimed to be role models in leading and maintaining standards of care for patients, but this was sometimes constrained by 
organisational processes, lack of authority and autonomy, and lack of support and preparation.

Conclusion Perceived differences between nursing and health service management means ward leaders' efforts to lead quality care are often undermined. Ward leaders must strike a balance between leading quality nursing care, in the context of organisational and political performance requirements, and the demands of administrative work, while often lacking autonomy and authority.

hospital management, leadership, nursing, nursing management, organisational behaviour, role conflict, ward sister

\section{Introduction}

Nursing leadership is the subject of considerable interest, but theory and practice have been poorly developed over the past few decades (Rafferty 1993, Stanley 2006). However, in recent years there has been a focus on the role of ward leader as pivotal to quality care at ward level (Royal College of Nursing (RCN) 2009, Department of Health (DH) 2010).

This article reports the results of a study that explored leadership experiences from the perspective of ward leaders, with supporting accounts from matrons, to examine how they fulfil the clinical and management aspects of their role and provide quality patient care. The term ward leader includes ward sisters, ward managers and charge nurses, while matron refers to the modern matron role (DH 2000).

\section{Background}

When nursing leadership fails, poor patient care, reduced patient safety and, ultimately, death can result (DH 2010). The RCN (2009) and the DH (2010) suggest the role of ward leader is pivotal to the leadership required to ensure quality patient care. Bolman and Deal (1991) argued that leadership is the solution to most of the problems in all organisations. Cook (2001) suggested that the same applies to nursing, and the NHS quality agenda continues to focus on the role of leadership in improving the quality of patient care (Gwyther 2009).

According to Howell and Avolio (1993), the more effective the leadership, the more effective the performance of organisations. There is also evidence, specifically in healthcare settings, that suggests there is a relationship between the effectiveness of leadership and performance that benefits patients, increases staff satisfaction and improves quality performance outcomes (Wong and Cummings 2007).

Storey (2004) argued that while leadership is a hot topic in organisational theory, research does not critically examine the link between leadership styles and organisational performance, while Currie et al (2009) suggested that this link is more a leap of faith than a confirmed fact.

The position of the nursing profession in the managerial hierarchy in healthcare is uncertain (Savage and Scott 2004). But whatever the definition of performance and quality, the effect of them on efficient leadership is clear, as, according to Cunningham and Whitby (1997), 'good leaders tended to produce good care, and poor leaders tended to produce poor care'.

\section{Ward leaders}

The importance of ward leaders has been consistently emphasised. For example, more than 50 years ago Scales (1952) described the role as pivotal to creating a philosophy of 
nursing, through postholders' attitudes, behaviours and standards of care. Since then there has been extensive literature suggesting that ward leaders are crucial in setting standards of care and quality in ward environments (Doherty 2003, Pegram et al 2013).

Almost two decades ago Salvage (1999) asked who 'hits the spot' in delivering the kind of nursing leadership that ensures provision of quality care, and gave the response 'behold the third way: the ward leader ... a powerhouse for change.' More recently Fenton (2013) described ward leaders as the 'glue in the system, negotiating the boundaries of healthcare in increasingly complex hospitals. The ward leader is responsible for everything that happens on the ward 24/7.' A better understanding of leadership at ward level is required to explore whether ward leaders believe they can enact the role outlined in RCN (2009) and DH (2010) policies.

Traditionally the role of ward leader was multifaceted and included setting standards, ensuring an appropriately skilled and trained workforce, and overseeing patients and their care, while retaining managerial oversight (Pembrey 1980, Bradshaw 2010). Lewis (1990) described ward leaders as the 'professional gatekeeper' of standards, protecting patients from poor practice, but added that if they are unsupported they cannot continue to do this. Worldwide the role has many common aspects, and ward leaders are the keepers of standards and drivers of quality care provision at ward level internationally (Gantz et al 2012, Pegram et al 2013).

However, Cook and Leathard (2004) argued that not only is there is a lack of literature that addresses effective nursing leadership, there is no definition. While the nursing leadership agenda supports the 'gatekeeping' concept in theory, the need for ward leaders to be keepers of standards, and to drive quality care provision in practice, is unclear. Further, as Klein (2013) notes, 'revelations about poor, sometimes scandalously so, care continues'. Given the challenges faced by ward leaders this is not surprising. Not only is there conflict, confusion and ambiguity surrounding the role, postholders are often illresourced and poorly supported to face complex and conflicting demands (Lewis 1990, Naughton and Nolan 1998).

The challenges faced by ward leaders are well-illustrated (Leah and Fenton 2012, Fenton 2013). For example, Firth (2002) found that ward leaders often experienced conflict between the managerial and clinical dimensions of their role, while Stanley (2009) reported that nursing leaders felt conflicted in their work because they were unclear what their role should look like.

Ward leaders do not feel empowered to change priorities and consistently react to the demands of a system (Regan and Rodriguez 2011). Further, McNamara et al (2011) and Regan and Rodriguez (2011) found that, despite the fact that the majority of ward leaders do an excellent job, failure to address issues around role conflict and disempowerment could impair the delivery of safe patient care.

There is little evidence on how to strengthen the role of ward leader. While there is no doubt that the role is valued in nursing literature, the special relationship ward leaders have with direct patient care means they are more likely to see the consequences of, for example, competing targets and policies. This suggests ward leaders are in a vulnerable position, which supports Doherty's (2003) view that the role is valued rhetorically but in reality it is at risk of becoming a 'scapegoat for performance failure'. This may also mean that ward leaders' authority and autonomy is undermined while at the same time they are endorsed as pivotal to the delivery of quality care. 


\section{Study}

\section{Aim and objectives}

The aim of the study was to explore the leadership of quality patient care from ward leaders' perspectives and develop an account of ward leaders' experiences of leading. The main objectives were:

- To investigate the possibilities and limitations of leadership at ward level.

- To explore the role of ward leaders in leading the delivery of quality care in a ward environment.

- To enquire into the experience of being a ward leader.

\section{Methodology}

A phenomenological qualitative methodology was used. The study site is a large, acute NHS teaching trust, typical of teaching hospital trusts in the UK.

\section{Sample}

The sample site employs more than 4,000 nurses and consists of two large campuses, which offer an extensive range of clinical specialties. The sample selection was straightforward because the role of ward leader in one trust was being studied, with supporting accounts from matrons.

Four matrons and 15 ward leaders across a range of specialties were interviewed. They were selected to provide depth and breadth, and to capture a range of clinical specialties. A sample matrix provided simple selection criteria for participants, and clinical areas were generalised as either medical or surgical, including adult and paediatrics. Those selected comprised almost one third of the ward leaders and matrons within the study site.

\section{Participants' experiences}

Each ward leader led a clinical ward, and each matron directly managed a minimum of four ward leaders. They had an aggregate of 80 years' experience in their roles. The interview questions sought to identify participants' insights into leadership at ward level and investigate how these related to leading quality care for patients, by exploring the role of leader and the challenges it presents.

\section{Data collection}

Semi-structured interviews enabled participants to talk about their experiences, thoughts and feelings. When ethical approval was granted a list was obtained of staff with the title of ward sister or charge nurse who managed a ward environment, and those with the title matron who directly managed a ward leader. Staff who met the inclusion criteria were invited to take part and volunteers were emailed an outline of the study. The ward leaders were also asked to share ward-level quality measurement documentation, which was discussed and collected as documentary evidence.

Consent was sought before the start of each interview, with a brief guide being used to encourage participants to discuss issues and enable a descriptive and in-depth conversation (Box 1). 


\section{Box 1: Interview guide}

1. Can you describe the role of a ward leader?

2. What are your experiences of leadership?

3. How does it feel to be a ward leader? (for ward leader group)

4. Can you describe your own leadership on the ward? (for ward leader group)

5. What do you think are the possibilities of leadership in a ward environment?

6. What do you think are the limitations of leadership in a ward environment?

7. What would help or hinder the role of ward leaders in the future?

8. How do you feel about the role of ward leaders in the future?

9. Prompts to use throughout interview - Can you give me any examples? And then what happened? Do you have anything else to add?

The interviews, which were recorded and transcribed, took place between August 2012 and January 2013. Background information such as number of years experience, number of beds on the ward, number of staff managed, number of consultants and number of clinical specialties housed on the ward was collected at the recruitment stage in the sampling matrix to enable comparison of the participants.

\section{Documentary evidence}

To enhance the qualitative interview component of the study, information from audits, action plans and qualitative nursing metrics were used as background information about the quality performance of the wards, and formed part of the data for analysis to answer the research questions.

\section{Ethics}

Ethical approval was obtained from the local research ethics committee in June 2012. The participants had the right of full disclosure to the study and to be informed that they would be studied, which ensured voluntary participation and informed consent. One of the main anticipated concerns for the participants was anonymity, for which assurance was given.

\section{Data analysis}

Familiarisation with the data was achieved through reading the transcripts, providing an overview of the interview content and early thematic analysis. A further methodological stepped approach was adopted for this process, following five stages (Pratt et al 2006):

1. Familiarisation, involving immersion in the data through listening to the interview recordings, transcribing, and rereading the transcripts.

2. Analysis to identify common statements about participants' views.

3. Application of codes to the data, creating provisional categories.

4. Comparison within and between cases, leading to the development of theoretical categories.

5. Interpretation of themes, involving the identification of relationships between codes, defining concepts, and developing strategies.

\section{Inclusion and exclusion criteria}

The inclusion criteria were that participants in the ward leader group held the title of ward sister, charge nurse or ward manager, and at the time of the study were employed to directly manage a ward in the study site. An inclusion criterion in the matron group was that they held the title of matron and managed a number of ward leaders in the study site.

The main exclusion criterion was staff who had worked within the researchers' management remit, which excluded five matrons and 17 ward leaders. 


\section{Reflexivity}

The researcher's interest in ward leadership stems from personal and practice-based recognition of the importance of the role in delivering quality patient care. This is combined with a commitment to promote the professionalism of nursing, develop nursing leadership and provide quality care. The researcher has over 28 years' nursing experience and at the time of the study was a divisional head nurse in an acute NHS trust on a one-year sabbatical to conduct this research.

\section{Findings}

Data revealed three main themes that influenced ward leaders' leadership experiences 'visibility and leading by example', 'empty conformity', and ' authority and autonomy'. These themes explain that the primary positive motivation of ward leaders is to lead their ward to deliver good quality patient care: 'What motivates me to come to work is the care the patient gets ... it's getting that leadership to make sure the staff are giving good care first, and not putting up with the fact that the patients don't get good care.' [Q1 we've deleted this and similar references throughout: (P11:L120-126) Presumably they refer to the page and line numbers in your study? If you wish to leave them in it would be best to have a link to an online version of your report so the reader could see them there.]

\section{Visibility and leading by example}

The ward leaders described themselves positively as leaders of their wards. One said they were 'very much the guardians of the quality of care that we give'. A matron called the role 'the leader of the ward, to actually lead the ward and try and maintain that quality', while another said 'this is what we want from a ward sister ... they have to be clinically based'.

Several factors directly inhibited or prevented this, but ultimately the ward leaders believed that being visible and leading by example was the main purpose of their role, and this was symbolic of how they managed the quality of care. Ward leaders had to be able to 'walk the walk', to be visible to staff and patients, and to display leadership: 'Leading by example and having high standards and making sure that everyone's aware of the standards ... because you've shown them ... if they see you've got really high standards and that's what you expect of yourself then that's what you expect of everyone else.'

There was agreement about what they believed was required to ensure they had the resources to enact the leadership behaviours needed to lead and drive quality care, and about the positive influences on the role: 'I class leading the team as being aware of what's happening, looking at where I can utilise my staff ... so they can see me as a role model, I wouldn't expect them to do anything that I'm not prepared to do. I'm on the ward clinically every day ... and that's the part of the job that appeals to me ... that I enjoy the most.'

Bradshaw (2010) suggested that ward leaders, in leading and maintaining standards of care, must be visible role models, and the participants recognised this as fundamentally important. The ward leaders developed their own moral value of leading by example in an attempt to find a balance between what they believe is important from nurses' perspectives and 'empty conformity' in terms of compliance with organisational constraints.

\section{Empty conformity}

Participants described empty conformity in terms of their level of compliance with organisational targets, such as audits and administrative tasks. Ward leaders experienced a sense of empty conformity in relation to having to focus on corporate goals and targets rather than patients' experiences, which highlights a gap between managerial values and participants' professional values. 
Participants described a situation in which ward leaders' values seemed at variance with political and organisational targets: 'If you sent me something rubbish to do I'd think all right I'll do it ... a complete waste of time. I don't agree with what you're asking me to do, but I'm not gonna change anything. So I might as well just do it ... you pay me to be here .... If you really want me to waste my time by transcribing this onto there .... Before, l'd just get angry about it and now I only argue if I really think it's out of order, what you're asking me to do. I just think "oh whatever".'

Various tensions and influences created a notion of empty conformity, which appeared to restrict participants' leadership opportunities. This created a divide between their perceived purpose of ensuring high standards of patient care and their daily duties. For example, while they appreciated the importance of documentation and audits, and the part these play in quality assurance, the volume of paperwork was perceived as taking them away from patients. This created a situation where 'it's difficult to get the balance right and you could actually almost say that at times the ward sister role is actually an admin and clerical job'.

One participant said: 'I'd like to say it's nursing based, but to be honest I think ... nowadays, it's more management paperwork.' This was supported by another who commented: 'You lose focus, you lose sight of who's important, and as a nurse from the ground-floor upwards the patient is the most important focus and we do lose that.'

Morton (2012) said it is nurse leaders at patients' bedsides who contribute to the 'unique nurse artist in all of us' and are the 'hallmark of bedside excellence and patient safety'. However, participants described how they were unable to enact this role consistently, mainly because of external forces and pressures to fulfil other duties. As one participant described it: 'I' $m$ between the devil and the deep blue sea.'

When discussing their feelings about being pulled away from patient care, one ward leader wished everyone would just 'leave me to do my job', which was to care for patients. This further supports the view that ward leaders are trying to find a balance in a situation in which the scales seemed to be tipped in favour of complying with targets rather than delivering care to patients.

One of the ward leaders was positive about a ward administrator who supported her with audits and paperwork: 'My role has been revolutionised ever since the ward administrator has been in post.' However, she also said: 'We do have audit overload.'

While the ward leaders recognised their own empty conformity to organisational targets, they did not believe they had the power or confidence to resist or challenge them. As one participant explained: 'They've taken a little bit of me away ... They've stolen a little bit of me away. I just think ... you're wasting my time ... I'm not gonna argue anymore, l'll just do it ... There are two ways of dealing with it aren't there? Your head can explode or you can move on, and at the end of the day, I think I do a good job.'

\section{Authority and autonomy}

Another constant thread was a feeling of lacking autonomy and authority. The ward leaders felt blamed, undermined and undervalued by the organisation and senior staff, left without a 'voice', and had a sense of resignation about this, increasing the dissonance between their values and the organisation. It appeared that they were desperately trying to prevent this from happening, by embodying their values and vision for patient care through 'leading by example'. One participant said: 'The ward sister can be that person who can set standards and monitor stuff and improve things.'

Mullally (2001) was often surprised by staff who told her they felt they were not allowed to do things, and ward leaders in this study described similar situations: 'We get made to do 
things we don't always agree with. As you've done the role a long time, sometimes it's not worth fighting it. You might as well just get on and do it.'

This notion of conflict was apparent when the ward leaders described how they were unable to be visible, or lead by example, by being 'out there' on the ward. This dissonance arose because the participants were so enthusiastic about their clinical, caring role and the quality of patient care: 'I feel frustrated ... I can't do everything I want to do. I used to think a ward leader was really important, it was their ward ... to lead the ward. During winter I just felt completely and utterly ... I felt like I couldn't do what I wanted to do. I wasn't high enough up in the food chain. I want to lead at a certain level, but because of organisational constraints I wasn't able to employ those.' Another participant said: 'I sit thinking ... don't say anything, nobody's gonna take any notice. It is a shame.'

Sergeant (2003) said that 'the loss of authority means the loss of not just patient care, but also a patient's advocate'. The participants expressed frustration at the number of administrative tasks they were responsible for, which undermined their autonomy. One said 'we're audited to death, we really are', while another commented 'I'm (senior) and I am doing something that I could train a monkey to do'.

The author argues that autonomy and authority are entwined, and are vital for nursing leaders to ensure improvement in the quality and efficiency of patient care. Paynton (2009) suggested that healthcare organisations worldwide are increasing nurses' professional responsibilities but are slow to recognise nurses as autonomous professionals with the authority to act. Paynton goes on to note that, ironically, the greatest formal power in healthcare organisations seems to lie with the people who spend the least time with patients.

\section{Discussion}

Findings from this study support Firth's (2002) view that the role of ward leader is one of the 'most critical in hospitals'. It could be argued, therefore, that it should be one of the most autonomous and authoritative. However, the role has evolved into an ambiguous management position that requires juggling of confusing 'multiple identities' (Doherty et al 2010). For participants in this study 'rhetoric alone has failed to convince ward sisters of the nature and worth of their dual role' (Doherty et al 2010).

The study also illustrates confusion around the correct balance between the different roles played by ward leaders in the context of others' expectations. More confusion seems to be centred on the leadership part of the role, given the postholders' divided loyalties. All participants referred to role ambiguity, and a common issue was a preoccupation with trying to balance 'everything' while conforming.

Ward leaders have an underlying fear of being blamed for not performing to required targets. There was a general sense that participants often found themselves attending to corporate goals and targets rather than patients' experiences, otherwise staff suffered the consequences. Currie (2006) called this notion of being blamed for poor performance a 'scapegoat' methodology. The dichotomy between meeting performance targets and ward leaders' values leads to a sense of insignificance and feelings of subordination, apathy and low professional self-esteem.

Over the years the role of ward leader has been identified as the linchpin, and one of the most important factors, in the efficiency and effectiveness of hospital wards (Runciman 1983). However, what have emerged are the stark differences in leadership values between ward leaders and senior trust staff, which indicates that the 'linchpin' role is misunderstood. 
The ward leaders felt a disconnect between their values of leadership of patient care and those of the hospital's hierarchy.

\section{Limitations}

Every effort was made to declare and limit potential biases and maintain trustworthiness, but a number of factors may have affected the study outcomes, including the researcher's role as a trust employee, her passion for the topic, using one trust as the study site, and the exclusion of other healthcare staff from the research sample.

Finding an NHS trust that was willing to allow the research to be conducted, and that helped the researcher access its staff easily, helped enormously. The researcher also received a great deal of support from her employer, who granted a year-long sabbatical which enabled her to gain full-time student status, detachment from the study site and time to undertake and complete the study.

Limitations were related to sample size and demographics. While the study focused on ward leaders and matrons in one trust, other ward nursing staff and multidisciplinary colleagues were not included. This was mainly because of the large number of participants who would have had to be included in the study, and because their views were not considered relevant at this stage of the research.

However, the perspectives of other healthcare professionals, including junior registered and non-registered nursing staff, could offer valuable insight into the role of ward leaders as the leaders of quality care. Future research could address this with multidisciplinary colleagues and other nursing staff, and compare its findings with this study.

\section{Implications for practice and conclusion}

Nursing leadership, and specifically the role of ward leader, is central to delivering quality (RCN 2009). This study supports that view and concludes that ward leaders strive to lead quality care, and to be role models, in the face of organisational and political performance requirements, and against competing demands of administrative work while often lacking autonomy and authority.

One of the recommendations of the inquiry into care at Mid-Staffordshire NHS Foundation Trust (DH 2013) was to have visible leadership on hospital wards and throughout the NHS. The researcher argues that ward leaders should be the visible nurse leaders on their wards, but the opportunity to achieve this has declined in recent years, as administrative duties have increased and support has decreased. The study found that ward leaders would be happier in their roles if they did not have to deal with the paperwork created by the administrative and management aspects of their jobs, aside from their job description responsibilities.

Most of the ward leader participants suggested that being given supervisory status would enable them to work directly with staff, give them more time to teach, and increase their capacity to monitor and maintain the quality measures required to improve care and patients' experiences. They believe they could then create healthier systems and processes that would deliver the best patient outcomes. The researcher supports this idea of supervisory roles, to enable ward leaders to lead quality patient care and triangulate information to understand the level of quality patient care delivered on their wards.

The ward leaders who took part in this study are passionate about nursing and have a common raison d'être to 'be there for the patients'. All the participants considered that it is their responsibility to maintain and lead the standards of quality patient care. 
Bolman L, Deal, T (1991) Reframing Organisations: Artistry, Choice and Leadership. Jossey Bass Publishers, San Francisco CA.

Bradshaw A (2010) Is the ward sister role still relevant to the quality of patient care? A critical examination of the ward sister role past and present. Journal of Clinical Nursing. 19, 23-24, 3555-3563.

Cook M (2001) The attributes of effective clinical nurse leaders. Nursing Standard. 15, 35, 33-36.

Cook M, Leathard H (2004) Learning for clinical leadership. Journal of Nursing Management. 12, 6, 436-444.

Cunningham G, Whitby E (1997) Power redistribution. Health Management. 14-15.

Currie G (2006) Reluctant but resourceful middle managers: the case of nurses in the NHS. Journal of Nursing Management. $14,1,5-12$.

Currie G, Lockett A, Suhomlinova O (2009) Leadership and institutional change in the public sector: the case of secondary schools in England. The Leadership Quarterly. 20, 5, 664-679.

Department of Health (2000) The NHS Plan: a Plan for Investment, a Plan for Reform. DH, The Stationery Office.

Department of Health (2010) Equity and Excellence: Liberating the NHS. DH, London.

Department of Health (2013) Robert Francis Inquiry report into Mid-Staffordshire NHS Foundation Trust. DH, London.

Doherty C (2003) Modernisation: the role of ward sisters and charge nurses. Nursing Standard. 17, 52, 33-35.

Doherty C, Gatenby M, Hales C (2010) Role of the ward sister: tensions, pressure, and opportunities. Nursing Standard. 24, 51, 35-40.

Fenton K (2013) Developing skills in clinical leadership for ward sisters. Nursing Times. 109, 9, 12-15.

Firth K (2002) Ward leadership: balancing the clinical and managerial roles. Professional Nurse. 17, 8, 486-489.

Gantz N, Sherman R, Jasper M et al (2012) Global nurse leader perspectives on health systems and workforce challenges. Journal of Nursing Management. 20, 4, 433-443.

Gwyther M (2009) The MT Interview: NHS CEO David Nicholson. www.managementtoday.co.uk/news/915846 (Last accessed: 13 February 2017.)

Howell J, Avolio B (1993) Transformational leadership, transactional leadership, locus of control, and support for innovation: key predictors of consolidated-business-unit performance. Journal of Applied Psychology. 78, 6, 891-902.

Klein R (2013) The NHS in the Age of Anxiety: Rhetoric and Reality - an Essay by Rudolf Klein. www.bmj.com/content/347/bmj.f5104 (Last accessed: 13 February 2017.)

Leah V, Fenton K (2012) Give sisters the freedom to be ward leaders and innovators. Nursing Times. 108, 16, 7-7.

Lewis T (1990) The hospital ward sister: professional gatekeeper. Journal of Advanced Nursing. 15, 7, 808-818.

McNamara M, Fealy G, Casey M et al (2011) Boundary matters: clinical leadership and the distinctive disciplinary contribution of nursing to multidisciplinary care. Journal of Clinical Nursing. 20, 23-24, 3502-3512.

Morton J (2012) Management and leadership at the bedside. Journal of Nursing Management. 20, 5, 579-581.

Mullaly S (2001) Leadership and politics. Nursing Management. 8, 4, 21-27.

Naughton M, Nolan M (1998) Developing nursing's future role: a challenge for the millennium. British Journal of Nursing. 7, 16, $983-986$.

Paynton S (2009) The informal power of nurses for promoting patient care. The Online Journal of Issues in Nursing. $14,1$.

Pegram A, Grainger M, Sigsworth J et al (2013) Strengthening the role of the ward manager: a review of the literature. Journal of Nursing Management. 22, 6, 685-696.

Pembrey S (1980) The Ward Sister - Key to Nursing: a Study of the Organisation of Individualised Nursing. Royal College of Nursing, London.

Pratt M, Rockman K, Kaufmann J (2006) Constructing professional identity: the role of work and identity learning cycles in the customization of identity among medical residents. Academy of Management Journal. 49, 2, 235-262.

Rafferty A-M (1993) Leading Questions - a Discussion Paper on the Issues of Nurse Leadership. King's Fund, London.

Regan L, Rodriguez L (2011) Nurse empowerment from a middle-management perspective: nurse managers' and assistant nurse managers' workplace empowerment views. The Permanente Journal. 15, 1, 101-107.

Royal College of Nursing (2009) Breaking Down Barriers, Driving up Standards. The Role of the Ward Sister and Charge Nurse. RCN, London.

Runciman P (1983) Ward Sister at Work. Churchill Livingstone, New York NY.

Salvage J (1999) 'Supersister' is the way forward for nurses in need of supportive, creative leadership. Nursing Times. 95, 21, 22.

Savage J, Scott C (2004) The modern matron: a hybrid management role with implications for continuous improvement. Journal of Nursing Management. 12, 6, 419-426.

Scales M (1952) Handbook for Ward Sisters (First Edition), London: Ballilliere Tindall and Cox. In Christian S, Norman I (1998) Clinical leadership in nursing development units. Journal of Advanced Nursing. 27, 1, 108-116. 
Sergeant H (2003) Managing Not to Manage: Management in the NHS. Centre for Policy Studies. London.

Stanley D (2006) In command of care: clinical nurse leadership explored. Journal of Research in Nursing. 11, 1, 20-39.

Stanley D (2009) Leadership and management: a new mutiny? In Bishop V (ed) (2009). Leadership for Nursing and Allied Health Care Professionals. Open University Press, Berkshire, England.

Storey J (ed) (2004) Leadership in Organizations - Current Issues and Key Trends. Routledge, London, New York.

Wong C, Cummings G (2007) The relationship between nursing leadership and patient outcomes: a systematic review. Journal of Nursing Management. 15, 5, 508-521. 